\title{
Social relations in a mixed group of mules, ponies and donkeys reflect differences in equid type
}

\author{
Leanne Proops ${ }^{\mathrm{a}, *}$, Faith Burden ${ }^{\mathrm{b}}$, Britta Osthaus ${ }^{\mathrm{a}, 1}$ \\ a School of Psychology, University of Exeter, EX4 4QG, UK \\ ${ }^{b}$ The Donkey Sanctuary, Sidmouth, Devon EX10 ONU, UK
}

\section{A R T I C L E I N F O}

\section{Article history:}

Received 16 September 2011

Received in revised form 21 February 2012

Accepted 22 March 2012

\section{Keywords:}

Affiliation

Dominance

Equine

Hybridization

Social behaviour

\begin{abstract}
A B S T R A C T
Donkeys and mules are frequently kept as companion animals for horses and ponies, with these different equids often being considered a homogenous group. However, the extent to which domestic equids form inter-specific bonds and display similar social behaviour when living in a mixed herd has not previously been studied. Here we compare the social organization of these three (sub)species when housed together, providing the first systematic analysis of how genetic hybridization is expressed in the social behaviour of mules. A group of 16 mules, donkeys and ponies was observed for $70 \mathrm{~h}$ and preferred associates, dominance rank and the linearity of the group's hierarchy was determined. The different equids formed distinct affiliative groups that were ordered in a linear hierarchy with ponies as the most dominant, mules in the middle ranks and donkeys in the lowest ranks. Within each equid subgroup, the strength of the hierarchy also varied. Thus in the present study, the three (sub)species displayed different social organization and levels of dominance and preferred to associate with animals of the same equid type, given the opportunity. These results suggest that different domestic equid (sub)species display variations in social behaviour that are likely to have a strong genetic basis.
\end{abstract}

(C) 2012 Elsevier B.V. All rights reserved.

\section{Introduction}

There are distinct differences in the social organization and behaviour of wild asses and horses yet their domestic cousins are often housed together as companion animals or a homogenous group (Linklater, 2000). Part of the necessary adaptation to domestication is an ability to cope with changeable and varied social structures and undoubtedly, when no other member of the same species is present, donkeys (Equus asinus), mules (Equus asinus X Equus caballus) and horses (Equus caballus) can form strong interspecific bonds (Budiansky, 1997; Jensen, 2006; personal observation). However, this does not mean that the nature of social relationships between different equid species is the same as it is among their own species. Although the effects of various factors such as age and sex on the relationships and dominance structures of domestic horses are well documented, the effect of equid type

\footnotetext{
* Corresponding author. Present address: Mammal Vocal Communication and Cognition Research, School of Psychology, University of Sussex, Brighton BN1 9QH, UK. Tel.: +44 01273 876602; fax: +44 01273678058.

E-mail addresses: leanne.proops@gmail.com, l.c.proops@sussex.ac.uk (L. Proops), faith.burden@thedonkeysanctuary.com (F. Burden), britta.osthaus@canterbury.ac.uk(B. Osthaus).

1 Present address: Psychology, Christ Church University, Canterbury CT1 1QU, UK.
}

(donkey, horse and mule) on these social relationships has yet to be investigated.

Equids form two types of social structure, Type I, female defence polygyny is seen in wild and feral horses that live in bachelor bands or family bands/harems consisting of a stallion (occasionally multiple stallions) and a number of breeding mares and their offspring. There is a strict, usually linear dominance hierarchy within the bands and between the bands in a herd (Linklater, 2000). Strong bonds between individuals are formed within these bands (Waring, 2003). In contrast, Type II, territorial defence polygyny is often seen in wild asses that are more territorial, with a dominant male tending to guard an area and breeding with females in the territory (Klingel, 1975; Linklater, 2000). These species are generally, but not always more solitary, with the only consistent and stable relationship (expressed through close affiliation) being between mother and offspring (Klingel, 1975). However, in feral and wild assess, females have been shown to remain within the habitat of a particular male, suggesting they may have formed some sort of social bond with that male without staying in close proximity to them, and stable groups have been observed when food is plentiful (Feh et al., 1994; Klingel, 1998; Moehlman, 1998). Conversely, territorial stallions have been observed in a feral horse population (Rubenstein, 1981). In general however, there are fairly consistent differences between the social organization of horses and asses and thus we may expect the two domestic species to reflect some of the different characteristics of their wild cousins. 
However, domestic equids are rarely given the opportunity to display fully the behaviour of their feral or wild cousins because many males are gelded and rarely are stallions kept with mares. A linear dominance hierarchy is generally maintained in domestic horse groups (Lehmann et al., 2003), however the factors that determine this hierarchy are not clear. One study found mares dominant over the geldings (although there were many more mares than geldings in the group) (Sigurjónsdóttir et al., 2003). Age and length of residency have also been found to be correlated with rank in most studies (Clutton-Brock et al., 1976; Heitor et al., 2006; Kimura, 1998; Sigurjónsdóttir et al., 2003; Tyler, 1972; Wells and Goldschmidt-Rothschild, 1979) although in some studies age did not determine rank for the adults (Houpt et al., 1978). Similarly, the influence of size or height on dominance in equids is debatable, with some studies showing a correlation (Houpt et al., 1978; Tyler, 1972) and others not (Clutton-Brock et al., 1976). What is clear from studies of both domestic, free ranging horses and feral horses is that preferred associates are of a similar rank (CluttonBrock et al., 1976; Kimura, 1998; Sigurjónsdóttir et al., 2003). To date there has been no published study of the social organization of domestic donkeys.

In this study we compare the social relationships and dominance behaviour of a small group of donkeys and ponies/horses with their hybrid, the mule. Comparison of the behavioural characteristics of closely related species and their hybrids has long been used as a way of studying the genetic determinants of behaviour (Purves et al., 2004). Hybrid animals show a variety of modifications compared to their parental species. If a trait is highly learnt or uniparentally inherited from the sex that provides care, one would expect behaviour to resemble that of the parent who raises the offspring. If a behaviour is biparentally inherited one would expect it to be intermediate of the parental species (Page et al., 2001). In other cases hybrids may demonstrate hybrid vigour, the combining of the best traits of the parent species into superior characteristics. This is often seen in the physical attributes of mules, bred for centuries to be stronger and have better endurance than a horse, combined with the steadfast disposition and surefootedness of the donkey (Travis, 1990). Hybrid vigour has also recently been demonstrated in their discrimination learning ability and also to a degree in their spatial reasoning during a detour task (Osthaus et al., Unpublished results; Proops et al., 2009). How the characteristics of horse and donkey social behaviour combine in the mule is unknown. This project recorded affiliative, dominant and submissive behaviours in a mixed group of 16 donkeys, mules and ponies in order to assess whether dominance rank, linearity of dominance structure and choice of preferred associates could be determined by equid type.

\section{Method}

\subsection{Subjects and study site}

The study was conducted at The Donkey Sanctuary's Axnoller Farm, Dorset, UK. The group consisted of sixteen animals, four mules ( 3 female, 1 male), four donkeys ( 1 female, 3 male), 7 ponies and 1 small horse (subsequently referred to as ponies) ( 1 female, 7 male). Ages ranged from 3 to 27 (mean $=15.56 \pm 7.81$ ). The group was formed in April 2005 thus length of residency within the group, a factor found to influence rank, was the same for all subjects (Clutton-Brock et al., 1976). Subject details including information about which subjects arrived at the sanctuary as bonded pairs, can be seen in Table 2 . Subjects were occasionally caught to be moved, groomed or for medical attention, but since their arrival at the sanctuary had not received much direct exposure to humans or any focused training beyond making sure they could be handled. At the time of observation, subjects were kept in an outdoor grass
Table 1

Ethogram of agonistic behaviours recorded.

\begin{tabular}{ll}
\hline Aggressive behaviours & Rapid opening and closing of the jaws, \\
gite & $\begin{array}{l}\text { With no contact. Neck arched, ears pinned } \\
\text { back. Often with a lunge. } \\
\text { Bite threat }\end{array}$ \\
Pursuit of another individual, usually with ears \\
pinned back, teeth exposed. \\
Ears laid back & $\begin{array}{l}\text { As described. Often occurs with a lunge. } \\
\text { Kind legs lift off the ground in an apparent }\end{array}$ \\
Kick threat & $\begin{array}{l}\text { Similar to kick but without the force or } \\
\text { extension to make contact. } \\
\text { Push }\end{array}$ \\
Pressing of the body against another in an \\
apparent attempt to displace them.
\end{tabular}

Adapted from McDonnell and Haviland (1995).

enclosure approximately eight acres in size. Subjects were turned out all year round and given haylage and straw as supplement to their grazing. A method of strip grazing was employed in which the perimeter fence of their enclosure was slightly extended each morning to provide a limited amount of fresh grazing daily.

\subsection{Data collection}

Data were collected over $70 \mathrm{~h}$ of observation between $7 \mathrm{am}$ and 7 pm during June-July 2006 by L.P. The observer sat as still as possible within sight of all animals at a vantage point just outside the enclosure. The observer was unknown to the group, did not interact with the subjects in any way and subjects quickly habituated to the observer's presence. All subjects were easily identifiable based on their morphology, size and coat colour. Ad libitum sampling was used to collect data on agonistic behaviour (Altmann, 1974). Seven types of aggressive and two types of submissive behaviours, taken from an ethogram of equid agonisitc behaviour, were recorded (McDonnell and Haviland, 1995; see Table 1). The method of strip grazing produced elevated levels of agonistic behaviour during the first few hours after the fresh grazing was introduced. A resource-based hierarchy could be observed during this time and the majority of the data on agonistic behaviour were collected during these hours. The incidence of aggression was low during the rest of the day.

To determine preferred associates, instantaneous scans of spatial positions were taken every 15 min (Altmann, 1974). Nearest neighbours and all animals within $5 \mathrm{~m}$ of each subject were recorded. If no animals were within $5 \mathrm{~m}$, the subject was scored as "alone". The length of the equid's body was used to estimate distances, one body length being approximately $1.5 \mathrm{~m}$. The nearest neighbour was defined as the animal that was closest, with any part of its body, to the head of the focal animal (Christensen et al., 2002; Kimura, 1998). The data were deemed to be independent as previous research had found that the probability of equids having the same nearest neighbour drops sharply after eight minutes (Feh and Wells, unpublished data, as cited in Feh, 1988). Proximity data were not recorded during the first hour after the fresh grazing was introduced to allow all incidences of aggression to be noted. It was also felt that proximity data recorded at that time would not have been representative of preferences in affiliation as there was a high degree of movement and displacements within the group. All incidences of mutual grooming were also recorded. 
Table 2

Subject profiles including dominance rank, preferred partner and companion on arrival at the sanctuary.

\begin{tabular}{|c|c|c|c|c|c|c|c|c|}
\hline Subject & Equid type & Sex & Age & Breed & Height (rank order) & Dominance rank & Preferred partner & $\begin{array}{l}\text { Companion on } \\
\text { arrival at sanctuary }\end{array}$ \\
\hline SP & Pony & M & 27 & Welsh pony & $11.1 \mathrm{~h}(3.5)$ & 1 & DO & - \\
\hline NI & Pony & M & 14 & Shetland X & $11.1 \mathrm{~h}(3.5)$ & 2 & DO & - \\
\hline DO & Pony & $\mathrm{F}$ & 21 & Cob cross & $14.2 \mathrm{~h}(1)$ & 3 & SP & DU \\
\hline GE & Pony & M & 17 & Native pony & $13 \mathrm{~h}(2)$ & 4 & DI & - \\
\hline TR & Pony & M & 17 & Shetland X & $9.2 \mathrm{~h}(15.5)$ & 5 & $\mathrm{AX}$ & LI \\
\hline $\mathrm{AX}$ & Pony & M & 10 & Welsh Sec. A & $10.1 \mathrm{~h}(11.5)$ & 6 & $\mathrm{TR}$ & SA \\
\hline MA & Mule & M & 19 & Unknown & $11 \mathrm{~h}(6)$ & 7 & MI & LU \\
\hline SO & Pony & M & 27 & Native X Shetland & $9.2 \mathrm{~h}(15.5)$ & 8 & DO & - \\
\hline DI & Pony & M & 3 & Welsh Sec. B type & $10.1 \mathrm{~h}(11.5)$ & 9 & GE & $\mathrm{BE}$ \\
\hline MU & Mule & $\mathrm{F}$ & 5 & Shetland X & $11 \mathrm{~h} \mathrm{(6)}$ & 10 & LU & - \\
\hline LU & Mule & $\mathrm{F}$ & 20 & Unknown & $10 \mathrm{~h}(14)$ & 11 & MU & MA \\
\hline MI & Mule & $\mathrm{F}$ & 22 & Unknown & $11 \mathrm{~h} \mathrm{(6)}$ & 12 & MA & - \\
\hline DU & Donkey & M & 10 & Donkey & $10.2 \mathrm{~h}(8.5)$ & 13 & $\mathrm{BE}$ & DO \\
\hline SA & Donkey & M & 12 & Donkey & $10.1 \mathrm{~h}(11.5)$ & 14 & LI & $\mathrm{AX}$ \\
\hline $\mathrm{BE}$ & Donkey & M & 3 & Donkey & $10.2 \mathrm{~h}(8.5)$ & 15 & DU & DI \\
\hline LI & Donkey & $\mathrm{F}$ & 22 & Donkey & $10.1 \mathrm{~h}(11.5)$ & 16 & SA & TR \\
\hline
\end{tabular}

\subsection{Data analysis}

\subsubsection{Dominance hierarchy}

Submission and dominance matrices were constructed based on the total frequencies of aggressive acts and submissive responses observed between each dyad. The method employed was that of Sigurjónsdóttir et al. (2003) where rank-order is determined by adding these matrices together and ranking animals according to the number of animals dominated. If two animals dominated the same number of animals the order was determined by the dominance relationship within that particular dyad, so called Hamiltonian ordering (de Vries, 1998). The effects of equid type and sex on ranking were determined using the Kruskal-Wallis nonparametric test. Height order was determined and animals of very similar height were given tied scores. The effects of age and height on rank within the mixed group were determined using Speaman's rho correlation (corrected for ties) and within each subgroup using Kendall's tau b correlation due to small sample sizes. The effects of height on rank in the pony subgroup was also calculated using Kendall's tau b correlation but was not calculated for the mule and donkey subgroups due to the small sample sizes and similar heights of the group members. Landau's linearity of dominance $(h)$, originally developed by Kendall (1962 as cited in de Vries, 1998) was calculated using the modification devised by Singh et al. (1992). Here calculations are not based on the total number of animals dominated but the proportion of wins over each animal; this was felt to be a better representation of situations where an animal does not win every encounter with another.

\subsubsection{Affiliations}

Two sociometric matrices were constructed, one showing the frequency with which each individual was recorded as the nearest neighbour of each of the other subjects (nearest neighbour matrix) and the other showing the frequency with which subjects were within $5 \mathrm{~m}$ of each other (proximity matrix). The scores were also converted to percentages of total observation time. The complementary analyses of hierarchical cluster analysis (Ward method using squared Euclidean distance) and multidimensional scaling (MDS) were used to identify subgroups within the herd. The Alscal program of MDS was used for analysis of converted dissimilarity matrices.

Correlates of the proximity data were determined by the Mantel T test for matrix comparisons (running 10,000 iterations). Hypothesis matrices were constructed for conspecificity (dyads scored as 0 for same equid group and 1 for different), rank distance, sex $(0=$ same sex, 1 = different $)$ and age difference. These were correlated with the proximity data (converted to a dissimilarity matrix).
The matrices of the two measures of proximity (nearest neighbour and subjects within $5 \mathrm{~m}$ of the focal animal) were also correlated using the Mantel T test to assess for any variations in the affilliative relationships recorded using these methods. SPSS v.11.0.2 and the zt software for matrix comparisons (Bonnet and Van de Peer, 2001) were used for data analysis.

\section{Results}

\subsection{Dominance hierarchy}

A total of 675 aggressive behaviours and 638 submissive behaviours were recorded. Of these, $9.06 \%$ were contrary to the established hierarchy. The frequency of threats was 0.60 per equidhour. Rank order can be seen in Table 2 . There was only one reversal in the hierarchy, where MU (rank 10) was found to be dominant over MA (rank 7). Significant differences in rank were found between equid groups ( $\mathrm{KW}, H=11.71, p<0.001$ ), but not between males and females (KW, $H=1.16$, NS). The ponies were the most dominant group, the mules were in the middle of the hierarchy and the donkeys were at the bottom. Rank was not correlated with age or with height within the mixed group (age: $r_{s}=0.33$, NS; height: $r_{s}=0.39, \mathrm{NS}$ ). Within the equid subgroups, rank was not correlated with age (ponies: $\tau=-0.37$, NS; mules: $\tau=0.67$, NS; donkeys: $\tau=0.33$, NS) but height was correlated with rank in the pony subgroup (ponies: $\tau=0.64, p<0.05$ ).

Linearity was determined for the whole group and the three equid subgroups. The whole group had a linearity score of $h=0.76$; for the ponies $h=0.83$; the mules, $h=0.42$; and for the donkeys, $h=0.08$. A score of 0.9 is considered a strongly linear hierarchy (Martin and Bateson, 1993), thus the group as a whole was reasonably linear; the ponies showed a strongly linear dominance hierarchy, the mules a mildly linear hierarchy and the relationship between the donkeys was not linear at all.

\subsection{Affiliations}

A total of 246 scans were recorded. A number of subgroups were present within the group and subjects showed distinct preferred associates. The matrices for the percentage of time subjects were recorded as nearest neighbours and the percentage of time subjects were within $5 \mathrm{~m}$ of one another yielded very similar results (Mantel T, $r=0.94, p<0.0002$ ). For simplicity, only the nearest neighbour data are presented here. Cluster analysis reveals two main subdivisions within the group, with the donkeys forming a distinct cluster apart from a much larger cluster containing the ponies and mules, see Fig. 1. Within the large cluster three subgroups were 


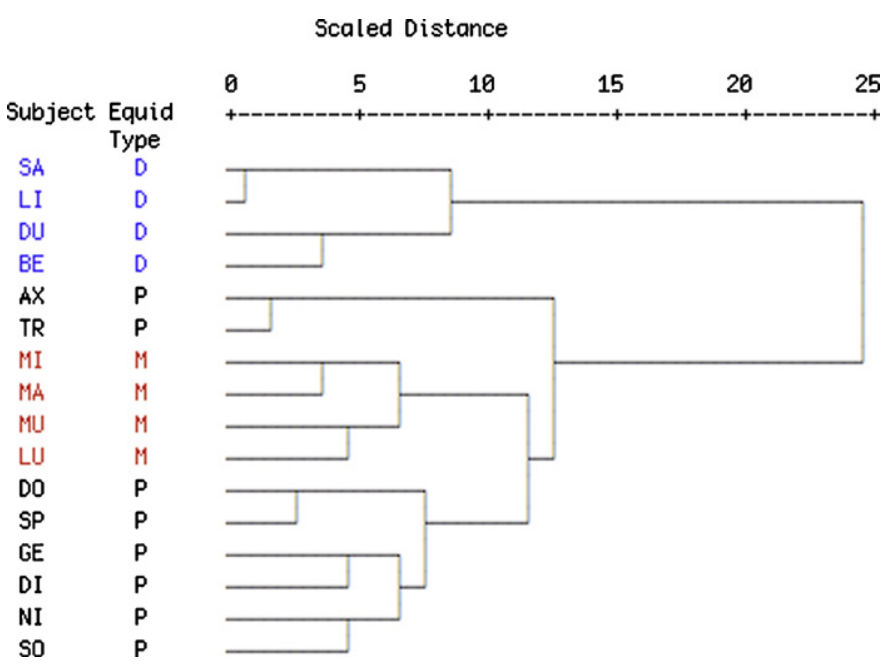

Fig. 1. Cluster analysis of proximity data showing subgroup formation.

evident with the mules forming their own group, AX and TR forming a distinct pair bond and a larger band containing the remaining six ponies. Thus all equids appeared to choose preferred associates from their own equid group.

MDS of the nearest neighbour data provided a two dimensional solution that was also a good spatial representation of the data, see Fig. 2. A Kruskal's stress score of 0.138 and Rsq score of 0.916 indicates the model is a fair goodness of fit and accounted for $91.6 \%$ of dispersion. Fig. 2 shows the distinction highlighted in the hierarchical cluster analysis (HCA) between the donkeys on the one hand and the mules and ponies on the other. Interestingly the mules are, as a group, positioned slightly closer to the donkeys than the majority of the ponies. Unlike the results from the HCA, a distinction between the mules and the ponies is revealed. In this case, TR and $\mathrm{AX}$, although still in their own subgroup, are placed in close proximity to the main band of ponies, whereas the HCA showed them having no preference for associating with the other ponies compared to the mules.

Affiliations were therefore found to be strongly correlated with equid type (Mantel T, $r=0.66, p<0.0002$ ) and rank (Mantel T, $r=0.51, p<0.0004$ ) but not sex (Mantel T, $r=0.09$, NS) or age (Mantel $\mathrm{T}, r=0.01, \mathrm{NS})$. Since rank itself is strongly associated with equid

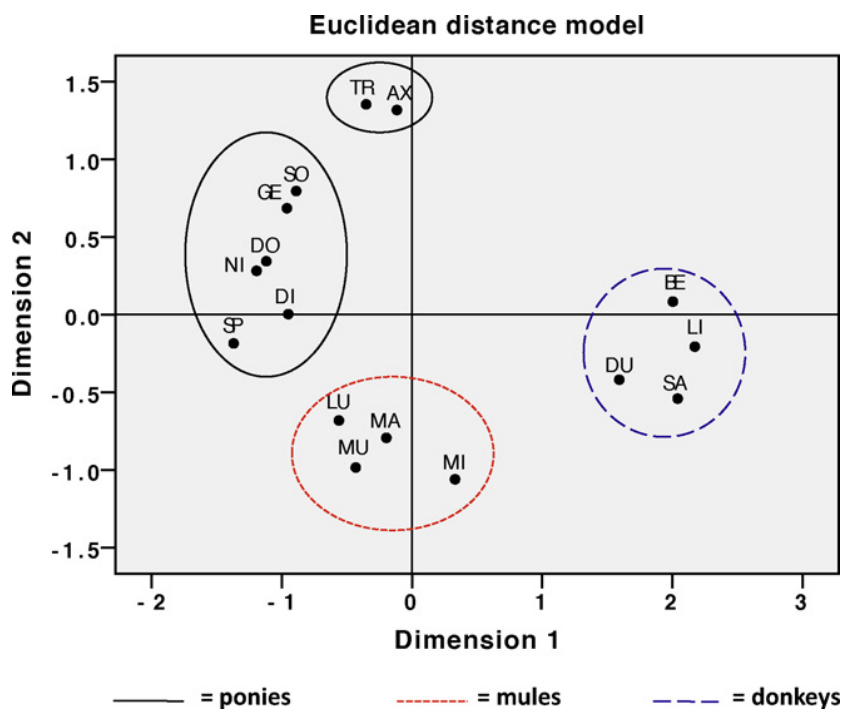

Fig. 2. Multidimensional scaling of proximity data, showing the extent of association between subjects. group, partial correlation coefficients were run to determine if these results were confounded. The correlation of proximity data with equid group, holding rank constant, continued to be significant (Mantel T, $r=0.54, p<0.0002$ ) as did the association of proximity and rank with equid group held constant, although with a reduction in the strength of the relationship (Mantel T, $r=0.26, p<0.01$ ). Thus although subjects tended to affiliate with individuals that were of a similar rank and of the same equid type, the strongest factor in choice of associates appears to be equid type.

It should be noted that the affiliations reported here do not reflect bonds formed prior to group formation in April 2005 (see Table 2). None of the subjects are now preferred partners (as defined as the individual most often their nearest neighbour) with individuals they arrived at the sanctuary with. The subjects that arrived at the sanctuary paired with an individual of a different equid type (four ponies and four donkeys: DO with DU, DI with BE, AX with SA and TR with LI) have now all formed new bonds with individuals of the same equid type and the two mules that arrived together, although still associates, have now formed stronger bonds with other mules in the group. Only six incidences of allogrooming (equivalent to 0.01 per equid hour) were recorded and no statistical analysis was performed due to insufficient data.

\section{Discussion}

The results show that there were significant differences in the social organization of the ponies, donkeys and mules within the mixed herd studied. Although the three equid (sub)species displayed the same types of social behaviour, the frequency with which these behaviours were observed varied. Thus rank, linearity of dominance relationships and choice of preferred partners were all determined primarily by equid type. Unlike other studies, age and sex were not correlated with rank or affiliation in this group, however, it is likely the small sample size and the unevenness of the sex ratio within the different equid groups would mask any genuine effects. What is clear is that the overriding determinant of social behaviour and social structure within the study group was equid type.

In the dominance hierarchy of the group, the ponies occupied the top ranks, the mules occupied the middle ranks and the donkeys occupied the lowest ranks. Rank was not correlated with height in the group as a whole, the fact that there were two ponies in the group (TR, rank 5 and SO, rank 8) that were considerably smaller than all of the mules and donkeys and yet dominant over (most of) them, serves to illustrate this point. Smaller, seemingly more aggressive feral pony mares have been observed to be dominant over larger individuals, despite a general tendency for size to be correlate with height (Tyler, 1972). It may be that genetic differences between ponies, donkeys and mules produce variations in aggressiveness that influence their dominance positions within a mixed herd. In addition, in our study the horses and ponies formed strong linear dominance hierarchies whereas the donkeys did not form a hierarchical subgroup. In the wild, horses generally live in larger and more stable groups than wild asses and so ways must be found to partition resources with the least aggression - the main function of a strict dominance hierarchy (Linklater, 2000; Kaufmann, 1983). In contrast, territorial male asses are dominant over all other conspecifics but no hierarchy is found among the other adults (Klingel, 1998). Thus if donkeys are not adapted to living within a linear dominance hierarchy they may not succeed in achieving high rank when placed in a heterospecific group with a (potentially more aggressive) species in which linear hierarchies are the norm. Further work comparing the temperament of these equid species may go some way towards explaining the observed differences in social dominance. 
The nearest neighbour data showed that strong affiliations were formed between animals from the same equid group and all subjects had preferred partners of the same type. Rank was also found to be a factor in choice of social partner, a pattern found in many species, and which probably serves to stabilize the group and maintain cohesion (Sigurjónsdóttir et al., 2002). However, the stronger determinant of affiliations was equid type, as demonstrated by the mule MA, who was rank 7 but still preferred to associate with the other mules that were ranked 10,11 and 12 . Similarly, if affiliations were based solely on rank then we would expect to see strong bonds between animals occupying adjacent ranks regardless of whether they were donkeys, mules or ponies. This clearly was not the case. Whether segregation based on equid type served to enhance or detract from the stability of the group is unclear, however rates of aggression ( 0.60 per equid hour) were well within the range found for horse-only groups (although this should be considered a conservative estimate as some subtle behaviours may have been missed) (Sigurjónsdóttir et al., 2003; Clutton-Brock et al., 1976; Rutberg and Greenberg, 1990). It should also be noted here that strip grazing is not comparable to the natural feeding behaviour of wild and feral horses as well as domestic horses kept on open pasture, and the frequency of agonistic behaviours reported here may reflect this difference

If one is to explain equine behaviour in terms of the ecology of their wild cousins then we may expect to find donkeys forming unstable groups and weaker affiliations compared to the ponies, yet the most strongly bonded pair (spending the most amount of time in each other's company) in this group was the donkeys LI and SA. The donkey group as a whole was also strongly associated with one another. When food is plentiful, feral donkeys and asses tend to form stable groups (Klingel, 1998; Moehlman, 1998), and since food is clearly also plentiful in a domestic setting, it may be that the relaxing of food finding demands allows donkeys to form stronger social bonds than is often seen in the wild. It may also be that the threat from the more dominant equid groups caused the donkeys to maintain stronger subgroup cohesion than they would if they were housed separately, a pattern observed in a small study of mule-horse interactions (Altmann, 1951). The finding that ponies are dominant over mules and associate preferentially with members of their own species, is also supported by the Altmann study. Similarly, a study of the dispersion of kulans, Asiatic Wild asses (Equus hemionus kulan) and takhi, Asian Wild horses (Equus przewalski) showed that the two species actively avoid one another, visiting areas at different times of day. The kulans completely stopped using areas that became horse strongholds, suggesting that the horses are the dominant species (Bahloul et al., 2001). Thus it would appear, from the limited data available, that, in certain circumstances at least, the species from which the domestic horse and donkey are descended also prefer to live in segregated groups.

Although the different equid (sub)species formed distinct affiliative subgroups, the mules did tend to spend more time in close proximity to the ponies compared to the donkeys. The cluster analysis showed two main groups, one consisting of the donkeys and the other of the ponies and mules. Why the mules preferred to spend more time with the ponies than the donkeys is unclear but may be based on a preference for the species that reared them. It has been reported that mules (hybrids of a female horse and a male donkey) are more likely to associate with other mules or horses than donkeys, whereas hinnies (hybrids from a female donkey and male horse) tend to prefer to associate with other hinnies or donkeys rather than horses (Travis, 1990). A comparison of the social behaviour of hinnies and mules would also be of interest as reported differences between these two hybrids have yet to be proved empirically and would help to clarify the strength of the genetic and learned components of equid social behaviour. Hybridization has produced in the mule an equid type that has its own unique and stable attributes and in general the social behaviour of the mules appears to reflect a "middle ground" between the parent species, showing that they possess a hybrid identity that is distinct from either species - a phenomenon observed in the mating systems of plants and some animals, being one of the mechanisms by which new species can be formed (Mallet, 2007; Hendry, 2009). While mules have been shown to demonstrate hybrid vigour in physical attributes and cognitive abilities (Travis, 1990; Proops et al., 2009; Osthaus et al., Unpublished results), this superiority does not appear to extend to social dominance.

The notion that equid social organization is strongly genetically determined is supported by the findings presented here (Linklater, 2000). However, in horses the strength and linearity of hierarchies as well as the number and strength of affiliations does vary between groups and so replication of our findings based on larger groups of equids in different locations, including more free-ranging populations, will be required before we can conclude that the differences in the social behaviour of the three equids groups reflects robust differences in the species as a whole. Despite some variation in the social structure and affilliative behaviour of different populations of horses and asses, the result from our domestic subjects do appear to reflect the widely observed differences in the social organization of their wild equid counterparts (Feh et al., 1994; Feh, 1988; Klingel, 1998; Linklater, 2000; Moehlman, 1998; Rubenstein, 1981). Aspects such as the variation in the linearity of the dominance hierarchies are consistent with the variations we may expect to see between the Type I and Type II species from which they are descended. Although replication with a larger sample size is required before any firm conclusions can be drawn, these results would indicate that despite five thousand years of domestication, and therefore similar selective pressures, donkeys and horses continue to show species variations. The fact that the mules were clearly an intermediate group between the two parent species lends further support to the notion that variations are genetically determined.

\section{Conclusion}

Mules, donkeys, horses and ponies are often kept together but the precise nature of their relationship has not been studied. Observational reports suggest that equids which have formed a strong bond with an individual of another equid type when housed as a pair, will quickly change preferred associates to an individual of the same equid type when given the opportunity (Burden, personal observation). Thus from a welfare perspective it is important to assess how different equids interact if they are to be housed as mixed pairs or groups. Moreover, the comparison of the social organization of donkeys and horses/ponies with their hybrid, the mule, provides insights into the ontogenetic and phylogenetic factors involved in the expression of social behaviour in equids (Linklater, 2000). In this study, distinct differences were found between ponies, donkeys and mules in their social organization. The ponies were the most dominant group and also had the most strongly linear hierarchy. The donkeys were the least dominant and did not have a hierarchical social structure. The mules showed social organization that was intermediate to that of their parent species. The animals clearly distinguished one another based on equid type and although subgroups of preferred associates were based in part on rank, the main determinate was equid type. It would seem that despite donkeys, ponies and mules often being housed together, they prefer to associate with members of their own equid type and should not be considered to be a homogenous group with the same social behaviour (Altmann, 1951; Bahloul et al., 2001; Linklater, 2000). 


\section{Acknowledgements}

We would like to thank all the members of staff at The Donkey Sanctuary's Axnoller farm for their willingness to facilitate this project. We are also grateful to Prof. Stephen Lea and Prof. John Endler for statistical advice and for helpful comments on the original manuscript and to the two anonymous reviewers for their helpful comments.

\section{References}

Altmann, J., 1974. Observational study of behavior - sampling methods. Behaviour 49, 227-267.

Altmann, M., 1951. A study of behaviour in a horse-mule group: with animal sociograms. Sociometry $14,351-3554$.

Bahloul, K., Pereladova, O.B., Soldatova, N., Fisenko, G., Sidorenko, E., Sempere, A.J., 2001. Social organization and dispersion of introduced kulans (Equus hemionus kulan) and Przewalski horses (Equus przewalski) in the Bukhara Reserve, Uzbekistan. Journal of Arid Environments 47, 309-323.

Bonnet, E., Van de Peer, Y., 2001. zt. Flanders Interuniversity Institute for Biotechnology, Ghent University, Ghent, Belgium.

Budiansky, S., 1997. The nature of horses: their evolution, intelligence and behaviour. Orion Books Ltd., London.

Christensen, J.W., Zharkikh, T., Ladewig, J., Yasinetskaya, N., 2002. Social behaviour in stallion groups (Equus przewalskii and Equus caballus) kept under natural and domestic conditions. Applied Animal Behaviour Science 76, 11-20.

Clutton-Brock, T.H., Greenwood, P.J., Powell, R.P., 1976. Ranks and relationships in highland ponies and highland cows. Zeitschrift Fur Tierpsychologie-Journal of Comparative Ethology 41, 202-216.

de Vries, H., 1998. Finding a dominance order most consistent with a linear hierarchy: a new procedure and review. Animal Behaviour 55, 827-843.

Feh, C., 1988. Social behaviour and relationships of Przewalksi horses in Dutch semireserves. Applied Animal Behaviour Science 21, 71-87.

Feh, C., Boldsukh, T., Tourenq, C., 1994. Are family groups in equids a response to cooperative hunting by predators-the case of Mongolian kulans (Equus hemionus luteus matschie). Revue D’Ecologie-La Terre Et La Vie 49, 11-20.

Heitor, F., Oom, M.d.M., Vicente, L., 2006. Social relationships in a herd of Sorraia horses. Part II. Factors affecting affiliative relationships and sexual behaviours. Behavioural Processes 73, 231-239.

Hendry, A.P., 2009. Speciation. Nature 458, 162-164.

Houpt, K.A., Law, K., Martinisi, V., 1978. Dominance hierarchies in domestic horses. Applied Animal Ethology 4, 273-283.

Jensen, P., 2006. Domestication - from behaviour to genes and back again. Applied Animal Behaviour Science 97, 3-15.

Kaufmann, J.H., 1983. On the definitions and functions of dominance and territoriality. Biological Reviews 58, 1-20.
Kimura, R., 1998. Mutual grooming and preferred associate relationships in a band of free-ranging horses. Applied Animal Behaviour Science 59, 265-276.

Klingel, H., 1975. Social organisation and reproduction in equids. Journal of Reproduction and Fertility 23, 7-11.

Klingel, H., 1998. Observations on social organization and behaviour of African and Asiatic Wild Asses (Equus africanus and Equus hemonius). Applied Animal Behaviour Science 60, 103-113.

Lehmann, K., Ellendorff, F., Kallweit, E., 2003. Dominance behaviour in horses - a literature review. Landbauforschung Volkenrode 53, 241-260.

Linklater, W.L., 2000. Adaptive explanation in socio-ecology: lessons from the Equidae. Biological Reviews 75, 1-20.

Mallet, J., 2007. Hybrid speciation. Nature 446, 279-283.

Martin, P., Bateson, P., 1993. Measuring Behaviour: an Introductory Guide. Cambrige University Press, Cambridge.

McDonnell, S.M., Haviland, J.C.S., 1995. Agonistic ethogram of the Equid bachelor band. Applied Animal Behaviour Science 4, 147-188.

Moehlman, P.D., 1998. Feral asses (Equus africanus): intraspecific variation in social organization in arid and mesic habitats. Applied Animal Behaviour Science 60 171-195.

Osthaus, B., Burden, F., Hocking, L. Proops, L., Unpublished results. Spatial perseveration by horses, donkeys and mules in a simple detour task.

Page, B., Goldsworthy, S.D., Hindell, M.A., 2001. Vocal traits of hybrid fur seals: intermediate to their parental species. Animal Behaviour 61, 959-967.

Proops, L., Burden, F., Osthaus, B., 2009. Mule cognition: a case of hybrid vigour? Animal Cognition 12, 75-84.

Purves, W.K., Sadava, D., Orians, G.H., Heller, H.C., 2004. Life: the Science of Biology, 7 th ed. Sinauer Associates, Gordonsville, VA.

Rubenstein, D.I., 1981. Behavioural ecology of island feral horses. Equine Veterinary Journal 13, 27-34.

Rutberg, A.T., Greenberg, S.A., 1990. Dominance, aggression frequencies and modes of aggressive competition in feral pony mares. Animal Behaviour 40 322-332.

Sigurjónsdóttir, H., Van Dierendonck, M.C., Snorrason, S., Thórhallsdóttir, A.G., 2003. Social relationships in a group of horses without a mature stallion. Behaviour $140,783-804$.

Sigurjónsdóttir, H., Van Dierendonck, M.C., Thórhallsdóttir, A.G. www3.vet.upenn.edu/labs/equinebehavior//hvnwkshp, Hólar, Iceland 2002. Friendship among horses: Rank and kinship matter. In: Proceedings of the Dorothy Russel Havemeyer Foundation Workshop, Horse behaviour and welfare.

Singh, M., D'Souza, L., Singh, M., 1992. Hierarchy kinship and social interaction among Japanese monkeys (Macaca fuscata). Journal of Biosciences 17, 15-27.

Travis, L., 1990. The Mule. J.A. Allen \& Co., London.

Tyler, S.J., 1972. The behaviour and social organisation of the New Forest ponies. Animal Behaviour Monographs 5, 85-196.

Waring, G., 2003. Horse Behavior. Noyes \& William Andrew, Norwich, NY-NY9.

Wells, S.M., Goldschmidt-Rothschild, B.V., 1979. Social behavior and relationships in a herd of Camargue horses. Zeitschrift Fuer Tierpsychologie-Journal of Comparative Ethology 49, 363-380. 